\title{
Two-Dimensional Echocardiographic Valve Measurements in Healthy Children: Gender-Specific Differences
}

\author{
M. V. Zilberman · P. R. Khoury • R. T. Kimball
}

Published online: 6 December 2007

(C) Springer Science+Business Media, LLC 2007

\section{Erratum to: Pediatr Cardiol}

\section{DOI: 10.1007/s00246-004-0736-z}

In the online and printed version of this article, the Tricuspid valve nomogram values in Figure 2 were featured incorrectly. They appear correctly here.

The online version of the original article can be found under doi: 10.1007/s00246-004-0736-z.

M. V. Zilberman · P. R. Khoury · R. T. Kimball Division of Cardiology, Cincinnati Children's Hospital Medical Center, Ohio, Cincinnati, USA

M. V. Zilberman $(\bowtie)$

Division of Cardiology, Department of Pediatrics, Wayne State University School of Medicine, Detroit, MI 48201, USA

e-mail: mzilberm@dmc.org
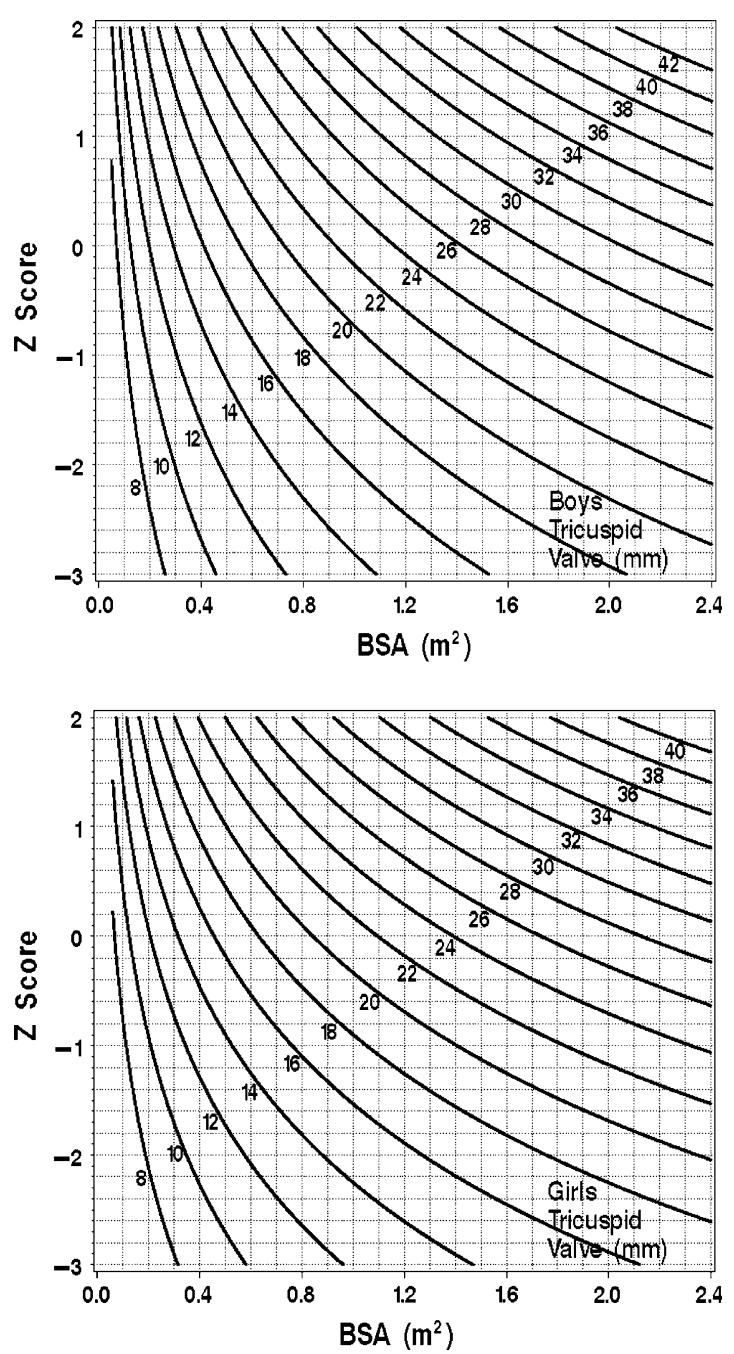

Fig. 2 Tricuspid valve $z$ value nomogram for boys (above) and (below) girls. BSA, body surface area 